\title{
Caltrans Embraces Complete Streets on the Central Coast
}

\author{
Adam Fukushima, PTP \\ Transportation planner for Caltrans in San Luis Obispo.
}

\begin{abstract}
In the field of transportation planning several countries, included the US, are moving towards building streets that accomodate different modes of mobility and are more pedestrian friendly. The author, a planner with Caltrans, writes about the concept of Complete Streets and how it is being implemented in the Central Coast.
\end{abstract}

O ver the last few years, there has been quite a buzz around the concept of Complete Streets. Coined by Barbara McCann almost ten years ago to replace the wonky term, Routine Accommodation, the concept has galvanized communities to think about planning roadways for all travelers including bicyclists of all comfort levels, people on foot, and those using public transit. To date, 26 states and 352 regional and local jurisdictions around the United States have adopted some form of Complete Streets policy, with strong efforts being made for adoption at the national level.

What do Complete Streets look like? There is no singular way to design them. Each one is different and must be appropriate to the function and context of the road. Typical Complete Streets features may include sidewalks, bike lanes, bike paths, curb extensions, more accessible and inviting bus stops, median islands, or simply better street lighting, landscaping or cautionary signs. In any location, the intent is to ensure that travelers of all ages and abilities can move safely and efficiently along and across the transportation network.

When picturing Complete Streets, the images that come to mind most readily are main streets in small towns or neighborhood streets with children playing, bicyclists cruising, couples strolling, and shoppers browsing. This image is in contrast to what most people associate with Caltrans, namely high capacity, high-speed freeways. However, while Caltrans operates many freeways and expressways in the state, Caltrans also operates a great number of conventional highways that function as rural roads or main streets. Acknowledging the needs of bicyclists and travelers on foot is nothing new for the Golden State. The California Vehicle Code and the Streets and Highways Code have long identified the rights of bicyclists and pedestrians.
These Codes establish legislative intent, stating that people of all ages using all different forms of transportation are able to travel, permitting them on all State facilities unless specifically prohibited. Bicyclists and pedestrians are legal users of all conventional highways and most expressways in California. Bicyclists are also allowed to travel on about 1,000 miles or 25 percent of the State's freeway miles.

In 2001, Caltrans issued a policy known as Deputy Directive 64 acknowledging the "need to accommodate non-motorized travelers as an important consideration in improving the transportation network." In 2008, Governor Schwarzenegger signed into law Assembly Bill 1358, the California Complete Streets Act, which required all cities and counties in California to plan for "a well-balanced, connected, safe, and convenient multimodal transportation network" upon the adoption of the circulation elements in their general plans. Several months later, Caltrans issued a revision to Deputy Directive 64 to make it more consistent with $A B 1358$ and to move from "accommo-

\section{Complete Intersections:} A Guide to Reconstructing Intersections and Interchanges for Bicyclists and Pedestrians

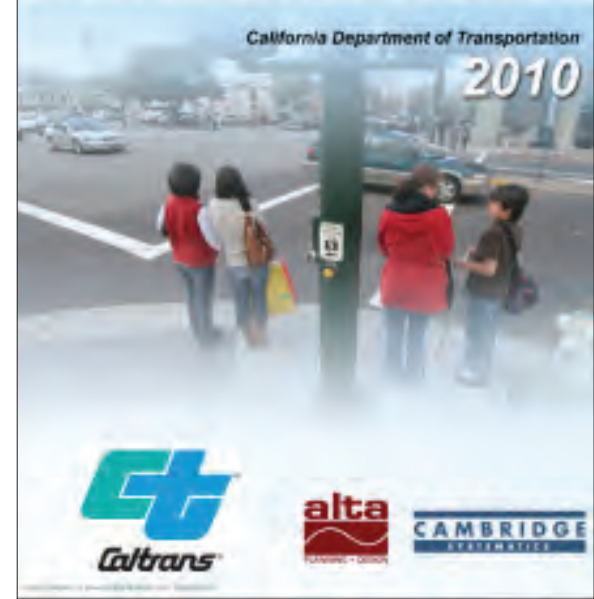
dation" to "integration" of transportation modes. It then followed with a Complete Streets Implementation Action Plan in 2010 that included 73 actions for all parts of the department.

One of the action items promoting Complete Streets implementation is through the Caltrans Complete Intersections Guide, which is a comprehensive and easy-to-follow booklet identifying actions that may help improve safety for pedestrians and bicyclists at intersections and interchanges, where mobility and safety concerns can be challenging. In addition, Caltrans also recently appointed two new members to the California Traffic Control Devices Committee representing non-motorized mobility interests. These key representatives will help ensure the concerns of all roadway 
users are considered in the decision-making process of setting standards for signs, traffic markings, and signals on all roads in California.

Also part of the Complete Streets implementation are recent updates to the Highway Design Manual and the Manual of Uniform Traffic Control Devices, both of which set State legal standards for how roads are designed and operated. The latest updates to these manuals have included significant changes to reflect Complete Streets.

\section{Projects on the Central Coast}

Along the Central Coast, Caltrans has been involved in a number of projects to improve travel for all road users. State Route 227 provides for regional travel between the cities of Arroyo Grande and San Luis Obispo and establishes a connection to US 101 via South Street. So-called because it was once the southern edge of San Luis Obispo when the roadway was built long ago, South Street today is a completely different corridor with development now existing on both sides of the street with mostly residential units mixed in with commercial and light industrial uses. Input from the community in the form of town hall meetings and a community task force indicated a desire for more pedestrian and bicycle accommodation as well as enhancements to reflect the residential character of the area. In response, Caltrans took advantage of an already programmed roadway rehabilitation project to make additional upgrades to the street.

Working together with the City of San Luis Obispo, State Route 227 was put on a "road diet" by reducing the four-lane arterial to two, adding center medians, pedestrian refuge areas, center left-hand turn lanes, and dedicated bus pullouts. With the extra roadway space, it was also possible to widen the existing bike lanes to better accommodate cyclists. The City of San Luis Obispo hopes to one day landscape the center medians to enhance the neighborhood context of the roadway. The landscaped medians may also provide "visual friction," an aspect of traffic psychology where the added vertical elements make the roadway appear narrower thus causing motorists to slow down.

Caltrans has constructed another road diet in Santa Barbara on State Route 225, a corridor known locally as Cliff Drive. Sparsely dotted with oil fields and pastures when it was constructed long ago, the corridor is now home to the City's residential and commercial community known as the Mesa. With a repaving project already approved and scheduled, Caltrans took the opportunity to work with the City of Santa Barbara to transform the four-lane state highway into a two-lane road with a center turn lane and new bike lanes.

Both of these road diet projects are part of a movement across the nation to look at ways to fit the roadway into the context of surrounding land uses. Nationally, road diets have been proven to work in areas where the average number of vehicles per day is below 25,000 . Even by reducing the number of lanes down to one in each direction, evidence has shown that slimmed down roads can improve the flow of traffic and better handle capacity due to the elimination of lane weaving.

Caltrans is also using the Central Coast as a testing ground for new innovations for improving travel for alternative transportation amenities. Originating in the Netherlands, bike boxes are increasingly found in cities across the United States including Long Beach, New York City, and San Francisco. The first bike box constructed by Caltrans was in 2010 in the City of San Luis Obispo. Located at the corner of Madonna Road and Higuera Street, the bike box serves as a tool to help decrease turning conflicts between motorists proceeding straight through the intersection and bicyclists turning left. By creating a dedicated area in front of queued vehicles, bicyclists are more visible.

Currently, Caltrans is building two Central Coast projects featuring bicycle paths with physical separation from automobile traffic. A bridge widening project over the Santa Maria River on US 101, highlights a new bicycle path that will improve bike

Figures 2 \& 3: State Route 227 (South Street) in San Luis Obispo before and

after Road Diet. In the future the City will landscape the raised median.
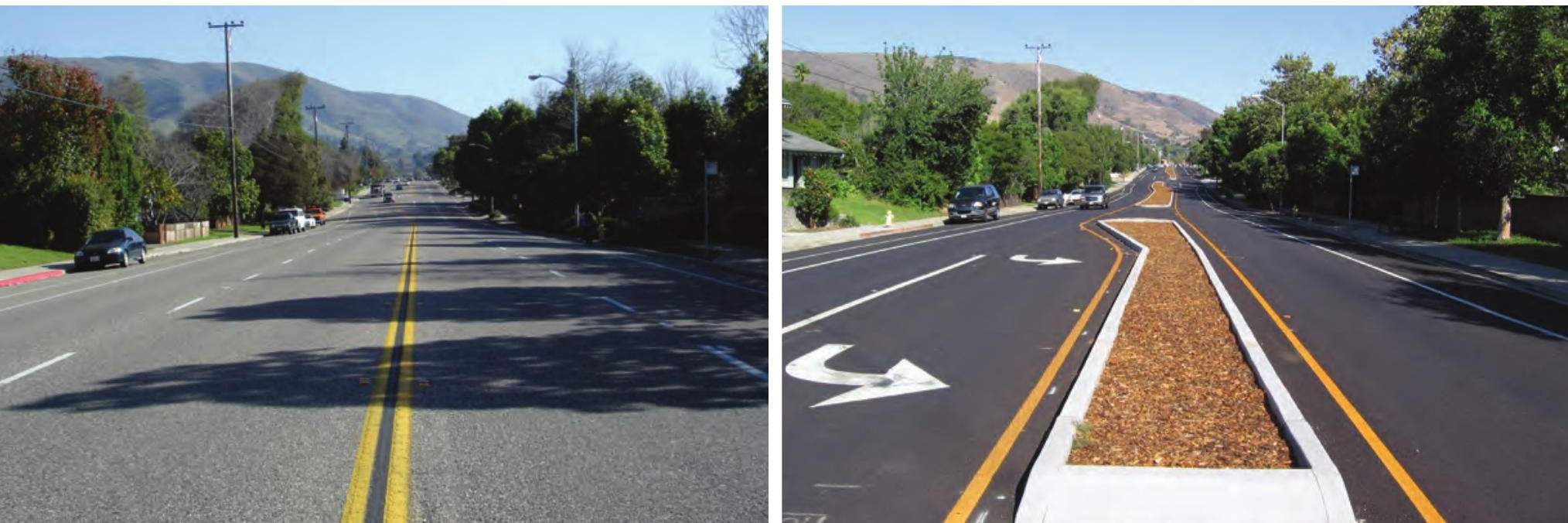


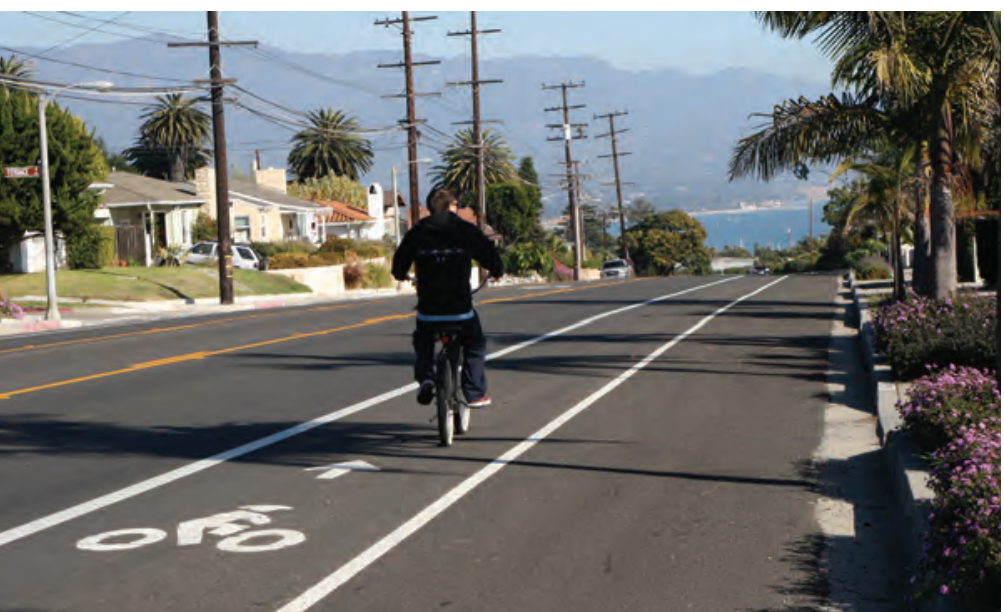

Figure 4: State Route 225 (Cliff Drive) in Santa Barbara with new bike lanes.

and pedestrian access between the City of Santa Maria and the community of Nipomo. Another project located in the community of La Conchita just south of the famous Rincon Point surf break in northern Ventura County, highlights a new high occupancy vehicle lane, and a bicycle path along the highway built to divert current bicycle travel along the freeway shoulder. The project also includes construction of a pedestrian underpass at the freeway in order to provide coastal access.

\section{Challenges}

Caltrans has made significant progress on providing Complete Streets. Moving ahead, Caltrans will continue to look for opportunities to make improvements that help all travel modes. However, no major effort in any organization is without its challenges. A major obstacle is balancing the needs of local communities and providing greater mobility for all Californians. Caltrans has the unique responsibility of making sure travelers can move efficiently and safely across regions and throughout the entire state while also remaining sensitive to local community concerns. For instance, most residents near a state highway would like to see slower speeds and less traffic volume. However, when residents need to commute to work or go on road trips for out-of-town vacations, they expect the state highways along the way to get them to their destination as quickly and conveniently as possible. Striking the balance between interregional and local travel needs is not an easy one.

Another challenge is the need to accommodate freight movement on state highways, which is vital to the vibrancy of our economy, whether hauling product from the port to large distributors, or just restocking the local supermarket. In fact, trucks comprise $82 \%$ of how freight is transported on the Central Coast (opposed to air, rail or pipeline). Trucks make it possible for residents to shop closer to home. Just taking a short trip to the corner store by foot or bike to pick up a carton of

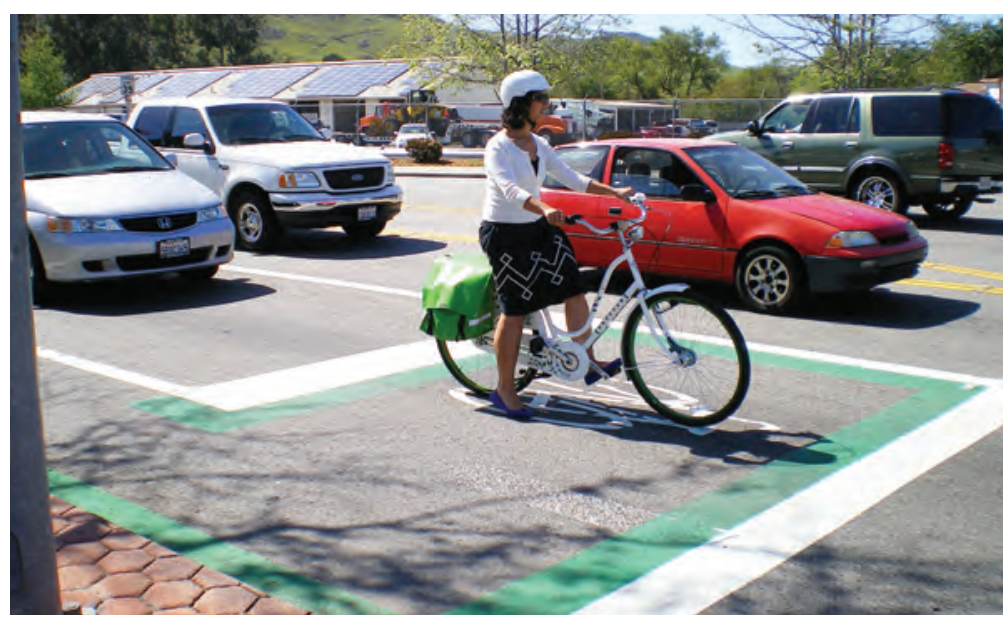

Figure 5: Bike Box in San Luis Obispo.

milk, requires delivery at some stage by a truck. However, considering the needs of trucks on state highways, which require wider traffic lanes and larger turn radii at intersections than passenger vehicles, presents a challenge for Complete Streets. In contrast, wider traffic lanes and turn radii usually mean longer crossing distances for pedestrians. Balancing the needs of all road users can be tricky and often calls for innovative thinking and creative solutions.

No less challenging for Caltrans is the lack of coordination between land use and transportation planning. While Caltrans owns and operates the state highway system, cities and counties are in charge of zoning and development that take place along the state highways. When the function of a state highway and the local vision for community development are not in sync, conflicts occur that can have big consequences for safety, access, congestion, and the quality of life for those who live and work there. It is therefore vital that Caltrans and local agencies work together toward a common vision of a highway corridor and its surrounding land uses. Additionally, by working together to better plan for the nexus of land use and transportation, progress is made toward fulfilling the goals of SB 375, the Sustainable Communities and Climate Protection Act.

\section{Opportunities}

Despite the challenges, there are a host of benefits that will result from pursuing every opportunity with Complete Streets. Planning for more versatile transportation networks and using Complete Streets practices can help ensure safer travel for all road users, including motorists. And by using design tools that accommodate a variety of modes and user abilities, we can help make other modes of travel more appealing; a critical step for California's future.

Population trends support a latent demand for Complete Streets. Given the increasing rate of retiring baby boomers, 
more and more seniors will need ways of getting around that are not dependent on the single occupant automobile. Additionally, more and more young people are also choosing to live in locations where they do not need a car. In fact, motorists age 21 to 30 now account for less total miles driven per year than they did in 1995. Providing transportation options for these trends will require better walkways, strategic use of transit, and smarter land use decisions.

The economic argument for Complete Streets is a strong one that illuminates an opportunity to save taxpayer dollars. By incorporating Complete Streets features into the initial design of a project, tax dollars can be saved on costly retrofits. Whenever a street is scheduled for repaving, it's also a good time to look for other improvements that can simultaneously be performed. For example, street upgrades can incorporate sidewalk construction or improved curb ramps to better accommodate pedestrians.
Moving forward, Caltrans will be evaluating its progress on Complete Streets to date and updating its Complete Streets Implementation Action Plan with new action items. The evaluation and update, scheduled for completion by the end of 2012, will identify successes, continuing challenges, and next steps to integrate all travel modes into the work of Caltrans. Meanwhile, continuing focus will be on departmental training and revisions to manuals that further support Complete Streets. Caltrans is working with communities to complete the streets, and you can expect to see more examples on the Central Coast in the near future.

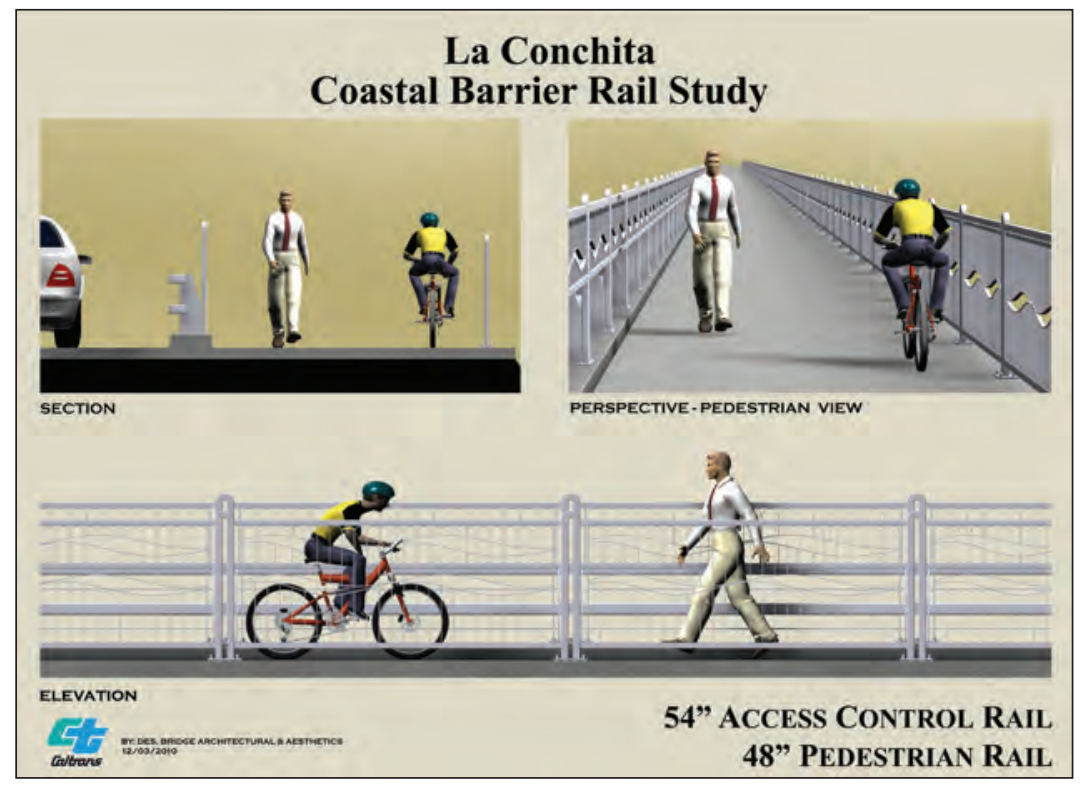

Figure 6: Rendering of La Conchita Bike Path along US 101. 